\title{
EUROPEAN UNION MATTERS
}

\section{Online Publication of Court Decisions} in Europe

\begin{abstract}
Although nowadays most courts publish decisions on the internet, substantial differences exist between European countries regarding such publication. These differences not only pertain to the extent with which judgments are published and anonymised, but also to their metadata, searchability and reusability. This article, written by Marc van Opijnen, Ginevra Peruginelli, Eleni Kefali and Monica Palmirani, contains a synthesis of a comprehensive comparative study on the publication of court decisions within all Member States of the European Union. Specific attention is paid on the legal and policy frameworks governing case law publication, actual practices, data protection issues, Open Data policies as well as the state of play regarding the implementation of the European Case Law Identifier.
\end{abstract}

Keywords: court cases; court decisions; electronic publishing; data protection; Open Data; European Union

\section{INTRODUCTION}

Nowadays, the internet facilitates the publication of vast quantities of court decisions, offering judiciaries an opportunity to increase visibility and transparency. Over the last two decades, governments and judicial authorities have developed different views to which extent and how these opportunities should be utilised. At the national level, courts and court administrations have to address issues like the scale of publication, selection procedures, data protection, copyright and re-use policies, quality and accessibility of information as well as the relationship with the private sector.

Within the framework of the project 'Building on the European Case Law Identifier', co-funded by the Justice Programme of the EU,' we conducted a comparative research regarding the on-line publication of court decisions in all Member States of the Europe Union. Limiting ourselves to repositories freely accessible to all citizens, we focused on three main themes - official policies and actual practices on publication, data protection and Open Data - and did additional research on citation guidelines and the implementation of the European Case Law Identifier.

The research is based on a comprehensive questionnaire which was answered between April and June 2016 by institutions from 23 Member States and followed by elaborate desk research. The full report of 178 pages was finalised in February 2017.2 Apart from topical chapters on the five themes mentioned, the report includes detailed analyses of each Member State, the Court of Justice of the
European Union, the European Court of Human Rights and the Boards of Appeal of the European Patent Organisation.

In this article we confine ourselves to a synthesis of the main findings regarding the national courts. We will discuss consecutively: national legal and policy frameworks regarding on-line publication, quantitative and qualitative aspects of current repositories, data protection, Open Data and the implementation of the European Case Law Identifier. We conclude with a small summary and some reflections.

Although some EU Member States are obviously more advanced than others, we withstood the temptation to make rankings: not only are there substantial differences between (types of) courts within one Member State, the weighing of the many aspects involved would be rather subjective and would distract the attention from the many improvements that are still possible everywhere. ${ }^{3}$

\section{LEGAL AND POLICY FRAMEWORKS}

Some Member States have specific legal provisions governing the publication of court decisions, in other Member States this is regulated by policy guidelines, e.g. a decision of a council for the judiciary or a ministerial decree, while others do not have a regulatory framework at all. But in case such regulatory frameworks do exist, they usually only cover specific courts. Hence, instead of comparing country by country, a subdivision has to be made as per type of court. While trying to respect the many specificities of judicial organisation 


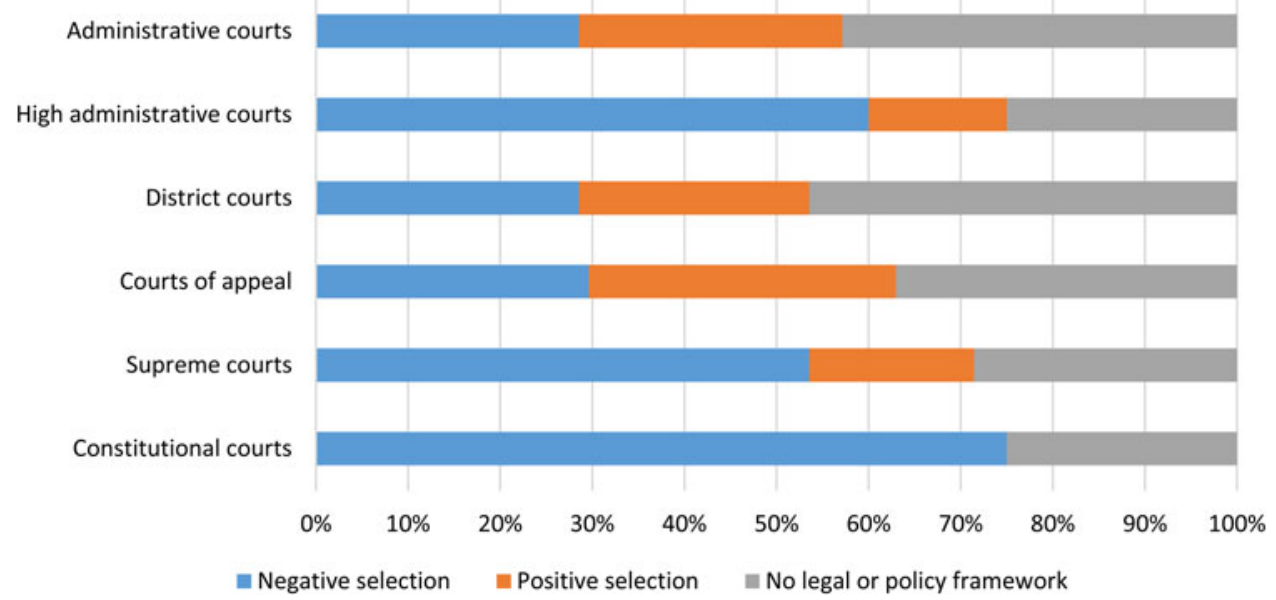

Figure I. Existence of legal \& policy frameworks. www.cambridge.org/core/journals/legalinformation-management

within the Member States (e.g. federal structures), we use the following typology: (I) administrative courts (first instance and appellate); (2) high administrative court(s); (3) district / first instance courts (civil and criminal jurisdiction); (4) courts of appeal (ibidem); (5) supreme courts (ibidem) and (6) constitutional courts.

Figure I gives an overview of the existence and nature of such legal or policy frameworks for these six court types. For a classification of the substantive provisions inspiration can be drawn from Recommendation $\mathrm{R}$ (95) II of the Committee of Ministers of the Council of Europe. ${ }^{4} \mathrm{~A}$ 'negative selection' is being made if, as a rule, all decisions are published, unless the grounds on which they are based are drafted with standard formula - e.g. rejections on procedural grounds - or if there are specific reasons not to publish a decision, e.g. to protect minors, or for reasons of state security or data protection. When following a 'positive selection', decisions are not published unless they meet specific criteria, formulated beforehand. Such criteria can be objective or subjective, broad or narrow, concrete or vague, procedural or substantive.

Negative criteria are generally formulated for the highest courts only: constitutional courts, supreme courts and high administrative courts. A legal obligation for a negative selection for decisions of (at least some of) the lower courts exists in eight Member States: Bulgaria, Denmark (not in force yet), Estonia, Latvia, Lithuania, Poland, Romania and Slovakia.

For reasons of internal efficiency and external transparency, both negative and positive selection criteria need detailed guidelines, either in the legal/policy framework itself, or in by-laws or administrative instructions. Since most negative selections have a legal basis, detailed guidelines are generally drafted, while for the positive selection such concrete criteria are more often absent, or at least not published on the internet. The Netherlands might serve as a best practice in this regard: the hybrid model (negative selection for the highest courts and positive selection for the other courts) is laid down in detailed guidelines, which are published on the internet. ${ }^{5}$

Information per Member State is displayed in Table I. This table also contains information on actual publication (discussed in the next paragraph), facilitating an easy comparison between the two.

\section{ACTUAL PUBLICATION}

The fact that a legal or policy framework exists doesn't necessarily imply that daily practice is in compliance with

\begin{tabular}{|c|c|c|c|}
\hline \multicolumn{4}{|c|}{ Legend } \\
\hline & General & \multicolumn{2}{|c|}{ Actual contents } \\
\hline 0 & Court type does not exist & -- & None or just very occasional \\
\hline \multicolumn{2}{|c|}{ Framework } & - & $\begin{array}{l}\text { Viore than occasional, Dut no substantial } \\
\text { selection }\end{array}$ \\
\hline Abs & Legal/policy framework absent & + & Substantial selection \\
\hline Pos & Framework with positive selection & ++ & All, or according to negative criterion \\
\hline Neg & Framework with negative selection & & \\
\hline
\end{tabular}


Table 1. Information per Member State and court type on legallpolicy framework, actual publication and number of web sites.

\begin{tabular}{|c|c|c|c|c|c|c|c|c|c|c|c|c|c|}
\hline & \multicolumn{2}{|c|}{ Constitutional court } & \multicolumn{2}{|c|}{ Supreme court } & \multicolumn{2}{|c|}{ Courts of appeal } & \multicolumn{2}{|c|}{ District courts } & \multicolumn{2}{|c|}{$\begin{array}{l}\text { High administrative } \\
\text { court }\end{array}$} & \multicolumn{2}{|c|}{$\begin{array}{l}\text { Administrative } \\
\text { courts }\end{array}$} & \multirow{2}{*}{$\begin{array}{c}\text { All courts } \\
\begin{array}{c}\text { Number of } \\
\text { websites }\end{array}\end{array}$} \\
\hline & Framework & $\begin{array}{l}\text { Actual } \\
\text { contents }\end{array}$ & Framework & $\begin{array}{l}\text { Actual } \\
\text { contents }\end{array}$ & Framework & $\begin{array}{l}\text { Actual } \\
\text { contents }\end{array}$ & Framework & $\begin{array}{l}\text { Actual } \\
\text { contents }\end{array}$ & Framework & $\begin{array}{l}\text { Actual } \\
\text { contents }\end{array}$ & Framework & $\begin{array}{l}\text { Actual } \\
\text { contents }\end{array}$ & \\
\hline Belgium & Neg & ++ & Pos & + & Pos & -- & Pos & -- & $\mathrm{Neg}$ & ++ & Abs & -- & 4 \\
\hline Bulgaria & Abs & ++ & Neg & ++ & Neg & ++ & Neg & ++ & Neg & ++ & $\mathrm{Neg}$ & ++ & 4 \\
\hline $\begin{array}{l}\text { Czech } \\
\text { Republic }\end{array}$ & $\mathrm{Neg}$ & ++ & Pos & + & Pos & - & Pos & - & $\mathrm{Neg}$ & ++ & Pos & - & 3 \\
\hline Denmark & 0 & 0 & Neg & - & Neg & -- & Neg & -- & 0 & 0 & 0 & 0 & 2 \\
\hline Germany & Neg & ++ & Neg & ++ & Abs & + & Abs & + & $\mathrm{Neg}$ & ++ & Abs & + & $>5$ \\
\hline Estonia & 0 & 0 & Neg & ++ & Neg & ++ & Neg & ++ & 0 & 0 & Neg & ++ & 2 \\
\hline Ireland & 0 & 0 & No & ++ & Abs & - & Abs & -- & 0 & 0 & Abs & -- & 3 \\
\hline Greece & Abs & -- & No & - & Abs & -- & Abs & -- & Abs & ++ & Abs & ++ & 1 \\
\hline Spain & Neg & ++ & Pos & ++ & Pos & ++ & Pos & -- & Pos & ++ & Pos & -- & 2 \\
\hline France & $\mathrm{Neg}$ & ++ & $\mathrm{Neg}$ & ++ & Pos & -- & Pos & -- & $\mathrm{Neg}$ & ++ & Pos & -- & 5 \\
\hline Croatia & Abs & ++ & Abs & + & Abs & - & Abs & - & Abs & - & Abs & - & 3 \\
\hline Italy & Neg & ++ & Neg & -- & Neg & -- & Neg & -- & $\mathrm{Neg}$ & ++ & $\mathrm{Neg}$ & -- & 3 \\
\hline Cyprus & 0 & 0 & No & + & 0 & 0 & Abs & - & 0 & 0 & 0 & 0 & 2 \\
\hline Latvia & Neg & ++ & Neg & ++ & Neg & ++ & Neg & ++ & $\mathrm{Neg}$ & ++ & Neg & ++ & 3 \\
\hline Lithuania & Neg & ++ & Neg & ++ & Neg & ++ & Neg & ++ & Neg & ++ & Neg & ++ & 3 \\
\hline Luxembourg & Neg & ++ & No & ++ & Abs & -- & Abs & -- & Abs & ++ & Abs & -- & 1 \\
\hline Hungary & Neg & ++ & Neg & ++ & Pos & + & Pos & + & 0 & 0 & Pos & + & 2 \\
\hline Malta & Abs & ++ & No & ++ & Abs & ++ & Abs & ++ & Abs & ++ & 0 & 0 & 2 \\
\hline Netherlands & 0 & 0 & Neg & ++ & Pos & + & Pos & + & Neg & ++ & 0 & 0 & 2 \\
\hline Austria & Neg & ++ & $\mathrm{Neg}$ & ++ & Pos & - & Pos & -- & $\mathrm{Neg}$ & ++ & Pos & -- & 2 \\
\hline Poland & Neg & ++ & Pos & ++ & Abs & -- & Abs & -- & Neg & ++ & Neg & ++ & 3 \\
\hline Portugal & Abs & ++ & Abs & + & Abs & + & Abs & + & Abs & ++ & Abs & + & 3 \\
\hline Romania & Neg & ++ & Neg & ++ & Neg & ++ & Neg & ++ & 0 & 0 & 0 & 0 & 4 \\
\hline Slovenia & $\mathrm{Neg}$ & ++ & $\mathrm{Neg}$ & ++ & Pos & + & Abs & -- & Pos & + & Abs & -- & 3 \\
\hline Slovakia & Neg & ++ & Neg & ++ & Neg & ++ & Neg & ++ & 0 & 0 & 0 & 0 & 3 \\
\hline Finland & 0 & 0 & $\mathrm{Neg}$ & ++ & Abs & - & Abs & -- & $\mathrm{Neg}$ & ++ & Abs & -- & 1 \\
\hline Sweden & 0 & 0 & Pos & - & Pos & - & Abs & -- & Pos & + & Pos & -- & 4 \\
\hline $\begin{array}{l}\text { United } \\
\text { Kingdom }\end{array}$ & 0 & 0 & Abs & ++ & Abs & - & Abs & -- & 0 & 0 & 0 & 0 & $>5$ \\
\hline
\end{tabular}


Administrative courts

High administrative courts

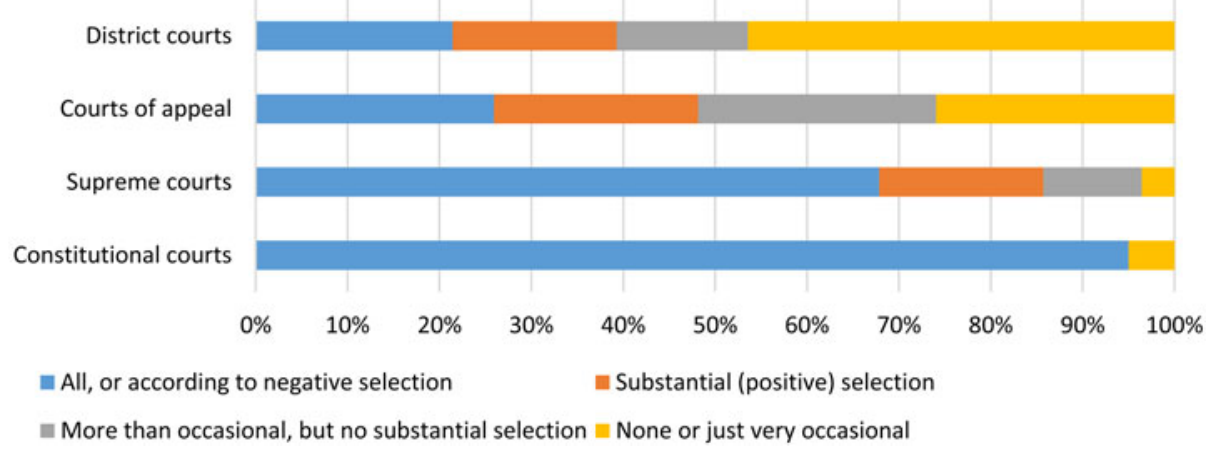

Figure 2. Actual publication by court type.

such a framework. Organisational or technical obstacles can impede proper implementation, or, the other way around, developed practices can be so satisfactory that a regulatory framework is not deemed necessary.

Figure 2 shows the actual publication by court type. It shows that nearly all constitutional courts within the EU publish all of their decisions. Also, nearly $80 \%$ of the high administrative courts and a little over $60 \%$ of the supreme courts publish (nearly) all their decisions. The situation for the district courts, the courts of appeal and the administrative courts is quite the opposite: in more than half of the Member States these courts do not publish decisions at all, or at least no substantial selection.

From an end-user perspective, judicial cooperation in disseminating published decisions is of great relevance: the more web sites one has to visit to attain a complete overview of current case-law developments, the more time-consuming, the more search interfaces and document formats to become acquainted with, and - probably - the harder it becomes to be satisfied in one's information need.

As can be learned from Figure 3 though, in a clear majority of the Member States more than one web site exists. Constitutional courts always have their own website/database, as do most supreme courts, high administrative courts and many specialised courts, while most often district courts, courts of appeal and administrative courts share a website or database. A portal web site for the whole judiciary sometimes offers the only access to all decisions (e.g. Malta, Finland) or all without the constitutional court (e.g. Spain), sometimes it coexists with court-specific web sites, where the latter offer different selections or differ in accessibility, e.g. with regard to metadata or search options (e.g. France, Germany).

Table I contains detailed information for all types of courts for all Member States regarding the legal/policy frameworks, actual publication and the number of public web sites.
Two decades ago, the legal information market was dominated by commercial players, on which even judiciaries themselves had to rely to keep up-to-date on case law developments. It is remarkable that today legal publishers do not play any (significant) role in the public databases that have now emerged. Exceptions exist in Italy and Germany, where access to some important case law databases that have been developed in public-private partnerships, is restricted to legal professionals and subscribers. Meanwhile, in most countries commercial publishers are free to re-use and re-publish decisions that have been disseminated via public court databases. In Lithuania publishers are even restricted to those; they are not allowed to publish decisions which are not in the public databases.

Most courts publish decisions always in full. Lower courts in Sweden and Austria often publish only the operative part, while some high jurisdictions in Austria and Italy produce a separate document containing the operative part or most important ruling, alongside the publication of the full text. With advancing technologies, digitization of historic repositories comes within reach;

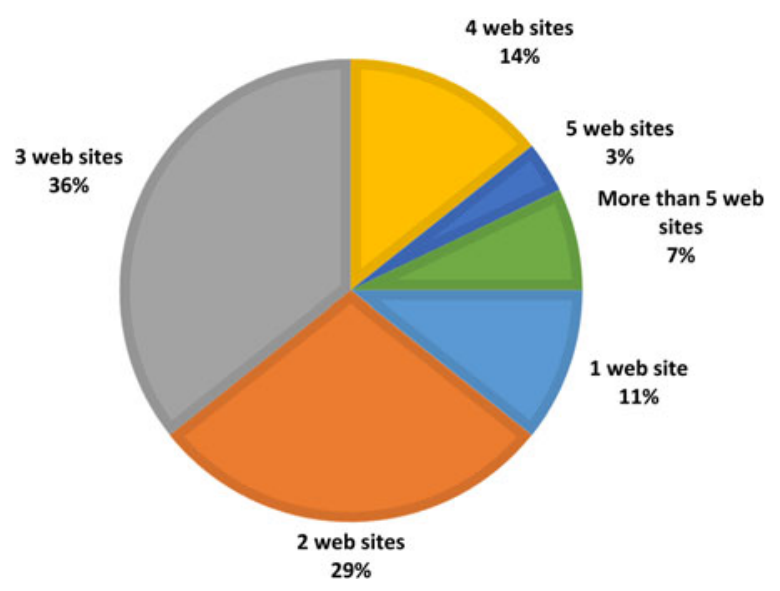

Figure 3. Percentage of Member States having the indicated number of public case law databases. 
Belgium and Cyprus offer examples of substantial historic collections having been scanned and made available for the public.

While 'access' to court decisions pertains to the extent to which court decisions have been made available electronically, 'accessibility' defines the ease with which the information contained in individual decisions or in a whole repository can be accessed. It encompasses topics like search engines and document formats, as well as the availability of translations and metadata. Here we focus mainly on the latter two. Metadata are essential to formulate search requests, filter the results or facilitate the understanding and contextualisation of a decision. A comparison of all the public repositories reveals that the number of metadata supplied varies between four and I4, with an average of 9.5. Identifying metadata, like name of court, date of decision and case number are always present, as well as - in many cases - type of decision, field of law, names of judges and chamber or division within the court. More descriptive metadata, like head notes, abstract and legal references are less widely available, and in most cases only for the highest jurisdictions. Most published decisions do not have in-text hyperlinks to legislation or referred case-law; exceptions can be found in e.g. Slovakia and Croatia.

One of the metadata often overlooked in the development of public case law databases is information on appeals. Since published decisions might be used by lawyers to back their arguments or by judges to motivate their own decisions, it is extremely important to know whether a decision is already irreversible (if its appeal term has passed) or whether it has been appealed and if so, whether it has been upheld, quashed or the appeal is still pending. Notwithstanding its importance, this information is not available in most databases. In Estonia the problem is solved by only publishing those decisions which are irrevocable. In the Netherlands formal relationships (like appeal or cassation) are visible in the database, but pending appeals are not. Also in Estonia, Croatia and Slovakia appellate relations are displayed. The Finnish Supreme Court has a separate database with pending cases.

Translations can be of interest for the public abroad, especially for case law regarding EU law, human rights, trade law or intellectual property. Only a small number of courts publish all or a substantial collection of their decisions in another language, mostly in English. Translations are most often supplied by constitutional courts, e.g. those of Slovenia, Poland, Czech Republic, Latvia and Croatia.

With a growing number of decisions published, for the average user (whether layman or lawyer) it becomes increasingly difficult to separate the wheat from the chaff, in other words: to distinguish the few decisions with jurisprudential value in a collection that might contain hundreds of thousands of cases. ${ }^{6}$ While the problem is ignored by most web portals, some courts show practices worth studying. Both the Finnish Supreme Court and High Administrative Court decide themselves on whether a decision establishes precedence; these decisions are included in two separate databases on Finlex, alongside databases with less relevant decisions. The Belgium Council of State follows a comparable practice, additionally, it only includes the most relevant paragraphs of the decision, linking to the full text in the general database.

\section{DATA PROTECTION}

Data protection in the European Union is still governed by the Data Protection Directive, ${ }^{7}$ but many already take the General Data Protection Regulation (GDPR) ${ }^{8}$ into account, which shall be fully applicable from 25 May 2018. In recital 26 the GDPR defines 'anonymised information' as: 'Information which does not relate to an identified or identifiable natural person or to personal data rendered anonymous in such a manner that the data subject is not or no longer identifiable,' while in everyday language the definition is generally less strict and 'anonymisation' means to delete, at least, direct personal data from a text with the intent to obscure the identity of natural persons. At the same time the GDPR introduces the term 'pseudonymisation', defined in article 4(5) as: 'The processing of personal data in such a manner that the personal data can no longer be attributed to a specific data subject without the use of additional information, provided that such additional information is kept separately and is subject to technical and organisational measures to ensure that the personal data are not attributed to an identified or identifiable natural person.' Hence, in anonymised as well as in pseudonymised information natural persons cannot be identified, but in the latter they are still (re-)identifiable by using additional datasets. Due to technological developments and continuous legal debate the distinction between the two is hard to draw, ${ }^{9}$ and the difference might be of relevance for the publication of court decisions as well, but for the objective of our current research it suffices to define 'anonymisation' as the removal of direct personal data from published court decisions.

With regard to anonymisation issues, it is not necessary to distinguish between courts of first, second or third instance, but only between different types of jurisdictions: constitutional, administrative and civil/criminal. A dedicated legal or policy data protection framework exists for the latter type in 16 Member States, while for constitutional and administrative jurisdictions such frameworks exist in six, respectively ten Member States. Actual practices with regard to anonymisation of court decisions are displayed in Figure 4.

It can be concluded that, in a vast majority of Member States, personal data are removed from published court decisions; obviously, legislators and courts consider that transparency of justice, legal research and judicial dialogue do not necessarily require the publication of personal data of those parties not professionally 


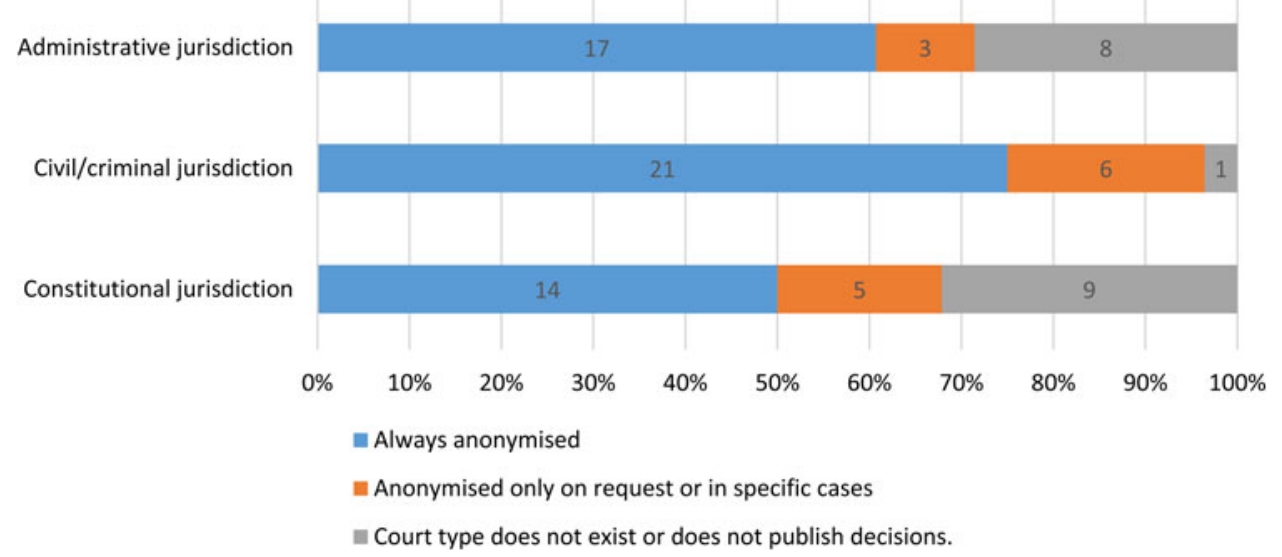

Figure 4. Anonymisation of court decisions in different jurisdictions.

involved in the case. Exceptions are certain countries with a common law tradition, where the 'open courts principle' conflicts with rigorous anonymisation. ${ }^{10}$

Differences also exist regarding the way in which anonymised personal data are displayed. Most courts use real or random initials. Complete obscuration - which renders a text quite illegible - is only used at a few courts. The practice of replacing personal data by labels indicating their role - a method that has the advantage of preserving readability while at the same time signaling which textual elements have been altered - is used in just a few Member States (see Figure 5).

When many decisions are to be published, implementing sufficient data protection is often one of the big hurdles, especially from a financial point of view. Hence, attempts to automate the business process can be witnessed at many courts. The process is purely manual in six Member States, while in seven Member States this is supported by software. Systems functioning mainly automated with only a manual check exist in eight Member States, and a system with which elements that are to be anonymised upon publication can be tagged during drafting exists in Cyprus only.
Table 2 supplies an overview per jurisdiction type / Member State of the existence of specific legal/ policy frameworks on anonymisation of court decisions, current practice as to the extent of anonymisation as well as the way anonymised data are represented in published documents.

\section{OPEN DATA}

The PSI directive ${ }^{\prime \prime}$ is based on the principle that public data should be made available for re-use upon request. 'Open Data' refers to the principle that public data should be made available pro-actively by public bodies for re-use, without restrictions on copyright, patents or other mechanisms of control. Re-use can be restricted on limited grounds, e.g. data protection. While court decisions indexed by the ECLI search engine (to be discussed in the next paragraph) should be available for reuse $^{12}$ via the EU Open Data portal, ${ }^{13}$ policies at the national level differ as to licence types and technical facilities.

With regard to the right to re-use court decisions published in public databases, Member States use different

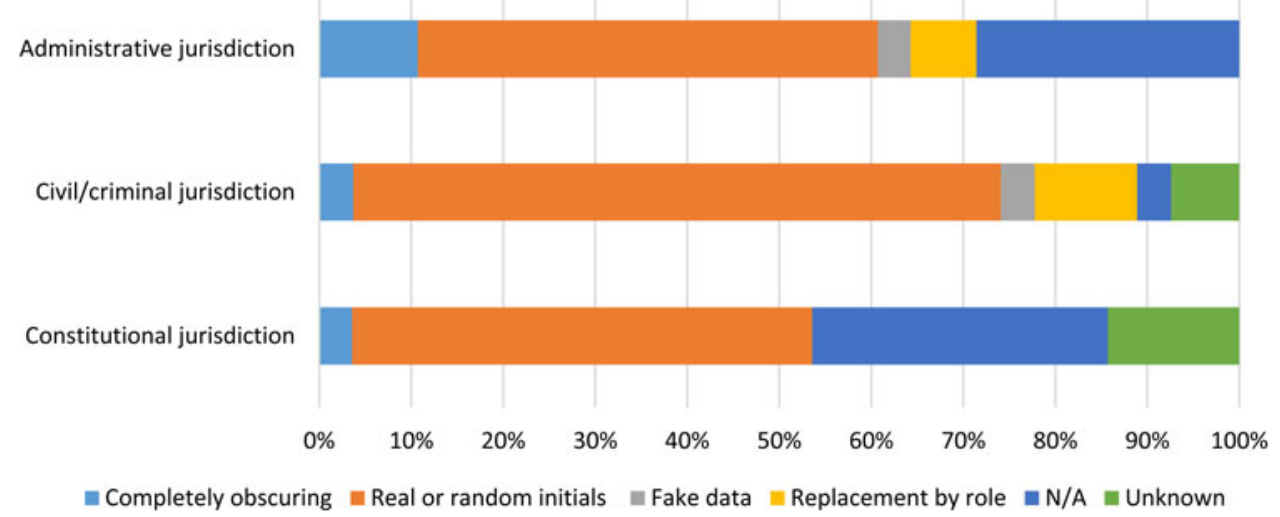

Figure 5. Textual representation of anonymised data. 


\begin{tabular}{|ll|}
\hline Legend & \\
N/A & Not applicable (court type does not exist or does not publish at all) \\
$?$ & No information available \\
Framework & No specific framework \\
No & Specific legal framework \\
Legal & Specific policy framework \\
Policy & \\
Factual Practice & Anonymisation by default \\
\cline { 1 - 2 } Def & Only on request of party or in specific cases \\
Req & Completely obscuring \\
Representation & Real or random initials \\
Obsc & Fake data \\
Init & Replacement by role \\
Fake & \\
\hline
\end{tabular}

\begin{tabular}{|c|c|c|c|c|c|c|c|c|c|}
\hline & \multicolumn{3}{|c|}{ Constitutional courts } & \multicolumn{3}{|c|}{ Civil/criminal courts } & \multicolumn{3}{|c|}{ Administrative courts } \\
\hline & $\begin{array}{c}\text { Frame- } \\
\text { work }\end{array}$ & Practice & $\begin{array}{l}\text { Represen- } \\
\text { tation }\end{array}$ & $\begin{array}{l}\text { Frame- } \\
\text { work }\end{array}$ & Practice & $\begin{array}{l}\text { Represen- } \\
\text { tation }\end{array}$ & $\begin{array}{c}\text { Frame- } \\
\text { work }\end{array}$ & Practice & $\begin{array}{c}\text { Represen- } \\
\text { tation }\end{array}$ \\
\hline Belgium & ? & Anon & Init & Legal & Def & Init & ? & Req & Obsc \\
\hline Bulgaria & ? & Def & ? & Legal & Def & Init & Legal & Def & Init \\
\hline $\begin{array}{l}\text { Czech } \\
\text { Republic }\end{array}$ & Legal & Req & Init & Legal & Def & Init & Legal & Def & Init \\
\hline Denmark & N/A & N/A & N/A & No & Def & Role & N/A & N/A & N/A \\
\hline Germany & No & Def & Init & No & Def & Init & No & Def & Init \\
\hline Estonia & N/A & N/A & N/A & Legal & Req & Init & N/A & N/A & N/A \\
\hline Ireland & N/A & N/A & N/A & No & Req & Init & N/A & N/A & N/A \\
\hline Greece & N/A & N/A & N/A & ? & N/A & N/A & No & Def & Obsc \\
\hline Spain & ? & Def & $?$ & No & Def & Fake & No & Def & Fake \\
\hline France & Policy & Def & Init & Policy & Def & Init & Policy & Def & Init \\
\hline Croatia & $?$ & Def & Init & Policy & Def & Init & Policy & Def & Init \\
\hline Italy & Policy & Req & Init & Legal & Req & Init & Legal & Req & Init \\
\hline Cyprus & N/A & N/A & N/A & No & Req & $?$ & N/A & N/A & N/A \\
\hline Latvia & N/A & Req & Init & Legal & Def & Role & Legal & Def & Role \\
\hline Lithuania & ? & Def & ? & Legal & Def & Init & Legal & Def & Init \\
\hline Luxembourg & $?$ & Def & Obsc & $?$ & Def & Obsc & $?$ & Def & Obsc \\
\hline Hungary & ? & Def & $?$ & Legal & Def & ? & N/A & N/A & N/A \\
\hline Malta & $?$ & Req & Init & $?$ & Req & Init & $?$ & Req & Init \\
\hline Netherlands & N/A & N/A & N/A & Policy & Def & Role & Policy & Def & Role \\
\hline Austria & Legal & Def & Init & Legal & Def & Init & Legal & Def & Init \\
\hline Poland & ? & Def & Init & ? & Def & Init & ? & Def & Init \\
\hline Portugal & No & Def & Init & No & Def & Init & No & Def & Init \\
\hline Romania & ? & Def & Init & Policy & Def & Init & N/A & N/A & N/A \\
\hline Slovenia & Legal & Req & Init & Policy & Def & Init & $?$ & Def & Init \\
\hline Slovakia & Legal & Def & Init & Legal & Def & Init & N/A & N/A & N/A \\
\hline Finland & N/A & N/A & N/A & ? & Def & Init & ? & Def & Init \\
\hline Sweden & N/A & N/A & N/A & Legal & Def & Init & Legal & Def & Init \\
\hline $\begin{array}{l}\text { United } \\
\text { Kingdom }\end{array}$ & N/A & N/A & N/A & No & Req & Init & N/A & N/A & N/A \\
\hline
\end{tabular}




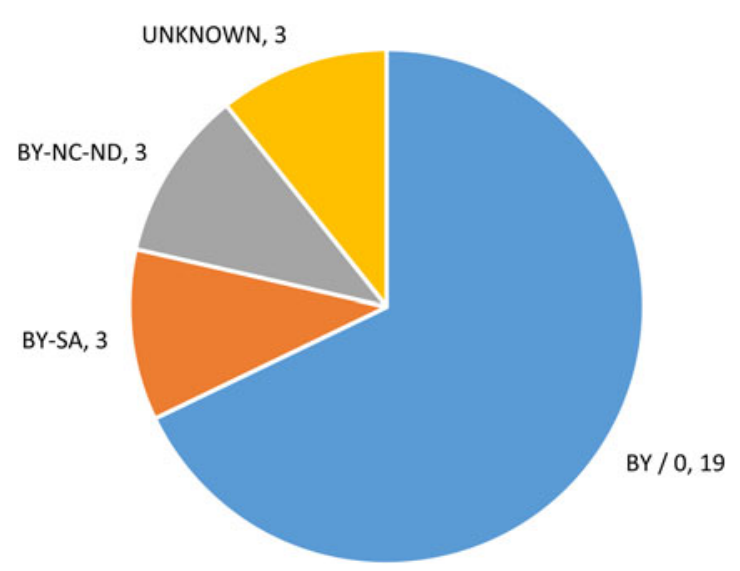

Figure 6. Licence types regarding the re-use of published court decisions.

types of licences. Legal restrictions can apply e.g. because of intellectual property rights or for data protection reasons. To be able to compare the licences, we mapped them to the Creative Commons licence types. As can be learned from Figure 6 most Member States impose none or small restrictions on re-use (licence CC-BY or CC0). Three Member States (Lithuania, UK and Italy) require that the information is not amended and the source is cited (BY-SA). Three Member States (Greece, Spain and Ireland), do not permit commercial re-use (BY-NC-ND). Some countries also require their re-users to respect data protection rules. In Member States where (most) decisions are published without anonymisation, bulk download is restricted by the use of the robots exclusion protocol (e.g. Ireland and the UK). ${ }^{14}$

Taking into account the volumes of published decisions, 'screen scraping' is very cumbersome for the re-user and establishes a performance risk for the information provider if many re-users are downloading the full database on a regular basis. Re-users are best served with technical solutions to facilitate bulk downloads and incremental updating; FTP access or a REST service are the better options. Nevertheless, only nine Member States offer such options; in some Member States also screen-scraping is blocked by the use of CAPTCHAs (Croatia, Bulgaria).

Even more than for the average site visitor, the document format is of particular importance for re-users: JSON, RDF and XML are computer processable formats, while Word and PDF (especially if scanned) create many challenges. Figure 7 outlines which document formats are available for re-use. It shows that not only the download facilities but also the further processing poses serious challenges for re-users.

\section{THE EUROPEAN CASE LAW IDENTIFIER}

Our research reveals that most Member States do not have formal or informal citation guides. Habitually, often

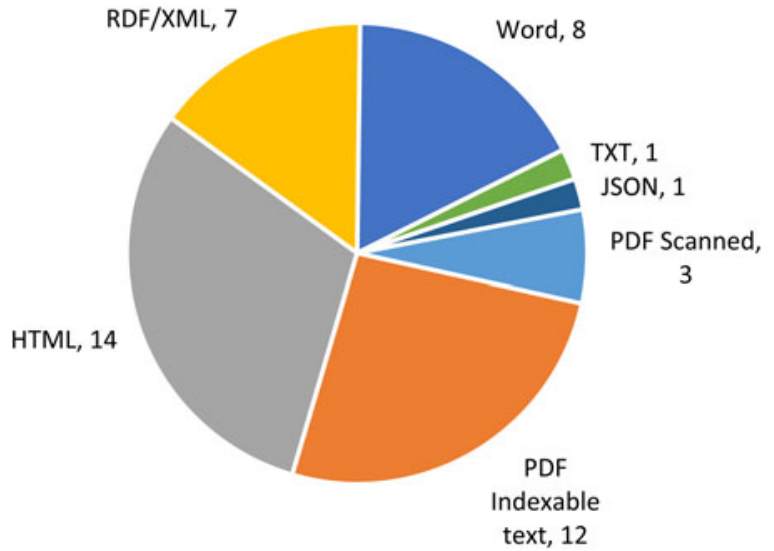

Figure 7. Available document formats for re-users. Since more than one format can be available the total is more than 28 .

case numbers or private identifiers (e.g. from commercial case law periodicals) are used. But case numbers can be ambiguous if more than one decision has been rendered in a case, private identifiers are not accessible to all and only assigned to reported judgments, and all these identifiers have a variety of spelling formats and are (hence) hardly processable by search engines, reference parsers or other electronic means.

To address this problem, also in a European context, the Council of the EU in 2010 established the European Case Law Identifier (ECLI). ${ }^{15}$ The univocal ECLI can be used to uniquely identify decisions of all courts within the European Union and of courts of European organisations, the accompanying set of metadata facilitates crossborder search, especially within the 'ECLI Search Engine.' ${ }^{16}$ This search engine, integrated in the European e-Justice portal, ${ }^{17}$ went live on 4 May 2016 and is developed and maintained by the European Commission. Currently, it has indexed more than 5 million court decisions that have an ECLI assigned, not only from official court websites, but also from republishers that offer enriched or translated versions - like the JuriFast database of the Association of Councils of State and Supreme Administrative Jurisdictions of the European Union. ${ }^{18}$

As of today, ECLI has been implemented in some or all of the case law databases of 15 Member States (Czech Republic, Germany, Estonia, Greece, Spain, France, Croatia, Italy, Netherlands, Austria, Portugal, Romania, Slovenia, Slovakia and Finland) and three European courts (Court of Justice of the European Union, European Court of Human Rights as well as the Boards of Appeal of the European Patent Organization). Another six Member States are at different stages of preparing an ECLI implementation (Belgium, Bulgaria, Denmark, Cyprus, Latvia and Malta).

Meanwhile, ECLI is being used increasingly for citations as well. The CJEU adds the ECLI to all references of its own case law and the Federal Administrative Court of Germany prescribes the use of ECLI in its own 
decisions. ${ }^{19}$ In the Netherlands ECLI has been assigned to all decisions that have ever been published by whichever publisher, ${ }^{20}$ the de facto style guide ${ }^{21}$ prescribes it as the preferred way of citing and it is added to the comply-or-explain list of the Dutch Standardization Board.

\section{CONCLUSION}

The wide variety of policies and practices is maybe one of the most important conclusions of our survey. First of all, there are substantial differences as to the existence of legal or policy frameworks on the on-line publication of court decisions. Some countries have extensive legislation, prescribing the publication of decisions within specific categories. Other countries have judicial policy guidelines while some have no legal/policy framework at all.

Although in general there seems to be a positive relationship between the existence of a legal framework and the number of decisions published, this is not a law of the Medes and Persians. And while a lenient publication policy might be assumed to be conducive for judicial transparency, the availability of vast repositories might be hampering the discoverability of decisions that reflect important legal developments. Large collections need ease of access, but even in this regard, differences can be witnessed. Some countries have one portal where all case law can be searched, others have many different websites; search functionalities range from absent to rather sophisticated.

Since court decisions often contain details about the most sensitive events in people's lives, data protection is one the most pressing issues. Many Member States have a policy of anonymising all decisions before they are published, but some jurisdictions follow a less stringent policy, and anonymise only on request or in specific types of cases. Differences can be observed also regarding the way in which anonymisation is done: some courts use (real or fake) initials, others replace the anonymised elements by meaningful labels or by fake data.

While published court decisions are important base materials for legal professionals, academic researchers, journalists and private companies in the legal information market, Open Data - the idea that public data should be freely available to everyone to (re-)use as they wish - has not gained a strong foothold yet within European judiciaries. In most countries technical facilities to ease harvesting the published decisions are absent, and the formats in which the documents are published do not allow easy processing by computers.

Since legal citations within and between court decisions and other legal sources are of the utmost importance for organizing legal knowledge, such references should be well-structured - and hence computer readable. Legal citation guides do not exist in most countries, although many jurisdictions do have a persistent practice. The European Case Law Identifier (ECLI) could play an important role in improving the European legal information architecture; it is being implemented in a growing number of jurisdictions.

Finally, it has surfaced from our research that proper access to court decisions benefits legal professionals, judiciaries, administrations and citizens, but that it not only requires balancing all interests involved, but also an informatical vision and substantial investments to reap the full benefits of what technology nowadays has to offer.

\section{ACKNOWLEDGEMENTS}

This publication has been produced with the financial support of the Justice Programme of the European Union. The contents of this publication are the sole responsibility of the authors and can in no way be taken to reflect the views of the European Commission.

\section{Footnotes}

' National or transnational e-Justice projects, JUST/20I4/JACC/AG/E-JU http://ec.europa.eu/justice/grantsI/calls/just_20I4_jacc_ ag_e-ju_en.htm.

${ }^{2}$ M. van Opijnen, G. Peruginelli, E. Kefali, and M. Palmirani, 'On-line Publication of Court Decisions in the EU. Report of the Policy Group of the Project 'Building on the European Case Law Identifier". http://bo-ecli.eu/uploads/deliverables/Deliverable\% 20WS0-DI.pdf. For this article, developments after February 2017 have been taken into account as much as possible.

${ }^{3} \mathrm{~A}$ ranking is made in e.g.: European Commission, 'The 2017 EU Justice Scoreboard' (p. 22-23), but when compared with our findings, many assertions can be disputed.

${ }^{4}$ Recommendation $\mathrm{R}(95)$ I I concerning the selection, processing, presentation and archiving of court decisions in legal information retrieval systems, https://wcd.coe.int/ViewDoc.jsp?id=538429\&Site=COE.

${ }^{5}$ https://www.rechtspraak.nl/Uitspraken-en-nieuws/Uitspraken/Paginas/Selectiecriteria.aspx

${ }^{6}$ See also M. van Opijnen, 'Towards a Global Importance Indicator for Court Decisions' (Legal Knowledge and Information Systems - JURIX: The Twenty-Ninth Annual Conference, Nice, December 2016).

${ }^{7}$ Directive 95/46/EC of the European Parliament and of the Council of 24 October 1995 on the protection of individuals with regard to the processing of personal data and on the free movement of such data [1995] OJ L28I/3I. 
${ }^{8}$ Regulation (EU) $2016 / 679$ of the European Parliament and of the Council of 27 April 2016 on the protection of natural persons with regard to the processing of personal data and on the free movement of such data, and repealing Directive 95/46/ EC [2016] OJ LII9/I.

${ }^{9}$ S.Y. Esayas, 'The role of anonymisation and pseudonymisation under the EU data privacy rules: beyond the 'all or nothing' approach' (2015) 6 European Journal of Law and Technology 2.

${ }^{10}$ As highlighted in A.T. $v$ Globe24h and Sebastien Radulescu 2017 FC II4.

1 'Directive 2003/98/EC of the European Parliament and of the Council of 17 November 2003 on the re-use of public sector information [2003] OJ L345/90, amended by Directive 2013/37/EU of the European Parliament and of the Council of 26 June 2013 amending Directive 2003/98/EC on the re-use of public sector information [2013] OJ LI75/I.

12 Expert group on Open Data of the Working Party on e-Law (e-Justice), 'Report of Expert Group on Open Data' II $1786 / 1 / 15$.

${ }^{13} \mathrm{http}: / /$ data.europa.eu/euodp, at the time of writing this dataset was not yet recorded.

${ }^{14}$ P. Magrath, 'Judgments as Public Information' (2015) I5 Legal Information Management 3.

${ }^{15}$ Council conclusions inviting the introduction of the European Case Law Identifier (ECLI) and a minimum set of uniform metadata for case law (2010) OJ CI27/I.

${ }^{16}$ https://e-justice.europa.eu/content_ecli_search_engine-430-en.do

${ }^{17}$ https://e-justice.europa.eu. This portal, intended as a one-stop-shop for legal information from the EU and Member States for and cross-border legal proceedings, was decided upon in the Multi-Annual European e-Justice Action Plan 2009-2013 (2009) OJ $C 75 / I$.

${ }^{18}$ http://www.aca-europe.eu/index.php/en/jurifast-en

${ }^{19}$ Bundesverwaltungsgericht 'Richtlinien für die Zitierweise und die Verwendung von Abkürzungen in den Entscheidungen des Bundesverwaltungsgerichts' (2014).

${ }^{20}$ W.J. Guo, From Case to Law. A study on how cases fulfil the role of source of law in the Netherlands and its implications for China and comparative law (University of Amsterdam 2014).

${ }^{21}$ M.H. Bastiaans a.o., Leidraad voor juridische auteurs 2016 (Wolters Kluwer 2016).

\section{Biographies}

Marc van Opijnen studied Law at the universities of Groningen and Leiden, and received his PhD at the University of Amsterdam (2014) with a multidisciplinary study about the online accessibility of court decisions. After having been affiliated to the judiciary for more than 10 years, currently he is adviser legal informatics at the Dutch Publications Office (UBR|KOOP). He is actively involved in various national and European projects for improving the access to legal information. He (co-) authored more than 40 publications on his fields of interest.

Ginevra Peruginelli is a researcher at ITTIG-CNR, with a degree in Law, a Ph.D in Telematics and Information Society, University of Florence and a Master's degree in Computer Science, University of Northumbria. For ten years she has been adjunct professor of legal informatics at the University of Perugia. She won two research fellowships at the Institute of Advanced Legal Studies, University of London and the Centre de recherche en droit public, University of Montréal. She is one of the editors in chief of the Journal of Open Access to Law by Cornell University.

Eleni Kefali holds a Law Degree from the Law School of the National and Kapodistrian University of Athens as well as a Master's Degree on International Studies (European Law, Public International Law and Private International Law) from the same university. Currently, she is the Justice Reform and Growth Director at the Institute for Justice and Growth (IJG) of the European Public Law Organization (EPLO). She has worked as a Lawyer and she has served as a Legal Officer - Counsel in several posts within the Greek public administration. She has participated in many Committees/Working Groups regarding legislative issues and IT matters both on national and on EU level.

Monica Palmirani is professor of legal informatics at University of Bologna, CIRSFID. She is a leader in the legal informatics with regard to Legal XML techniques for modeling legal documents both in structure and legal knowledge aspects, including ontology. On 2015 she received the Award from OASIS as Distinguished Contributor. She published more of 80 papers or books and she is coordinator of International PhD Law, Science and Technology programme. 